\title{
Evidence for fetal programming of obesity with a focus on putative mechanisms
}

\author{
Sarah H. Wild ${ }^{1}$ and Christopher D. Byrne ${ }^{2 *}$ \\ ${ }^{1}$ Public Health Sciences, University of Edinburgh, Teviot Place, Edinburgh, EH8 9AG, UK \\ ${ }^{2}$ University of Southampton School of Medicine, Developmental Origins of Health and Disease Division, \\ Level F, Centre Block, MP113, Southampton General Hospital, Southampton SO16 6YD, UK
}

\begin{abstract}
Obesity is associated with insulin resistance, the metabolic syndrome (a clustering of three or more of increased waist circumference, blood pressure, fasting glucose and fasting plasma triacylglycerol levels and reduced HDL levels), and a marked increase in the risk of type 2 diabetes and CHD. The impact of obesity differs between individuals, particularly between men and women and between ethnic groups. For example, in South Asians, although overall obesity is less prevalent, central obesity and the metabolic syndrome are more prevalent than in Europeans and this pattern is associated with the development of type 2 diabetes and CHD at an earlier age. It is important to examine individual risk factors contributing to obesity because they may have a different impact in population subgroups. Many factors contribute to the aetiology of obesity and there is increasing evidence to suggest that altered early development is one such factor and is associated with abnormal fat accumulation, the metabolic syndrome and type 2 diabetes in later life. The present review presents this evidence and discusses some of the mechanisms that may be involved in the pathogenesis of the programming of obesity.
\end{abstract}

Fetal programming: Diabetes mellitus: Obesity: Metabolic syndrome: Coronary heart disease

\section{Introduction}

Multiple factors contribute to the development of obesity and the relationship between these factors is complex. Man and animals only develop obesity if overall energy intake exceeds energy expenditure. Recent evidence shows the powerful influence of certain genes in predisposing affected individuals to develop obesity, particularly in association with exposure to environmental risk factors. In contrast, the influence of genetic factors to the development of obesity appears to be of limited relevance to the general population, with environmental factors having the major contribution. Factors other than environmental influences (for example, genes, programming) may be more relevant to fat distribution than to overall obesity (Rogers, 2003). Although obesity has been present in human populations throughout history, in the last 20 years there has been a marked increase in the prevalence of this condition. Obesity has an important adverse effect on longevity as exemplified by the fact that obesity and smoking are associated with similar reductions in life expectancy (Fig. 1; Peeters et al. 2003).

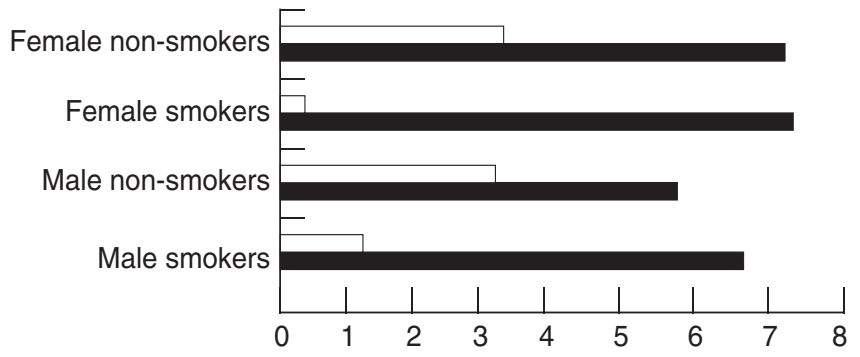

Years of life lost from age 40 (relative to BMI less than $25 \mathrm{~kg} / \mathrm{m}^{2}$ )

Fig. 1. Overweight and obesity in adulthood and its consequences for life expectancy; effect on premature death between 40 and 70 years of age. The cohort was 3457 adults aged $30-49$ years in 1950. They were followed-up for 40 years and the main outcome was life expectancy at 40 years of age. There were three groups: BMI $18.5-24.9 \mathrm{~kg} / \mathrm{m}^{2}$, BMI $25-29.9 \mathrm{~kg} / \mathrm{m}^{2}(\square)$, and BMI $30 \mathrm{~kg} / \mathrm{m}^{2}$ or greater $(\square)$. (Redrawn from Table 4 of Peeters et al. (2003) and reproduced with permission from Annals of Internal Medicine.)

\footnotetext{
Abbreviations: IGT, impaired glucose tolerance; PPAR, peroxisomal proliferator-activated receptor; WHR, waist:hip ratio. *Corresponding author: Professor Christopher D. Byrne, fax +44 2380 794945, email C.D.Byrne@soton.ac.uk
} 
The recent epidemic of obesity in many countries strongly suggests that man has not evolved to cope with the current 'environment'. Changes in our environment that contribute to the marked increase in obesity are relative physical inactivity and altered nutritional intake, both in terms of the quantity of food and the composition of nutrients consumed. It has been estimated that approximately $80 \%$ of the variation in one measure of obesity, BMI (as defined below), can be attributed to a combination of eating in excess of requirements and low levels of physical activity (Ravussin \& Bogardus, 2000). Increasing evidence supports the notion that an interaction occurs between eating in excess of requirements, low levels of physical activity and impaired early development, resulting in the increased prevalence of adult obesity (Ozanne et al. 2003). The purpose of the present review is to consider the evidence for, and the mechanisms of, programming of obesity during early development. The relevance of this phenomenon will be discussed in relation to the epidemiology of obesity, the metabolic syndrome (a clustering of three or more of increased waist circumference, blood pressure, fasting glucose and fasting plasma triacylglycerol levels, and reduced HDL levels), type 2 diabetes and CHD.

\section{Definition and measurement of obesity and body composition}

It is important to describe the definition of obesity because there are many different measures that can be used to assess it; for example, percentage body fat and fat distribution. Both of these factors are important because amount and locality of fat distribution have differing metabolic consequences. A variety of measurement tools are available for assessing overall obesity and fat distribution but it is beyond the scope of the present review to discuss these in detail. Some are more appropriate for screening large populations whereas others are suitable only for small studies designed to explore the mechanisms of disease. The simple methods that are useful for assessing large populations will be discussed in the present paper, in particular the relative merits of measuring BMI, waist circumference and the waist:hip ratio (WHR) as these are the commonly used measures in epidemiological studies that have examined the relationship between obesity and early development. The utility of these measurements will be discussed for various population subgroups. The most widely used measure of overall obesity in adults is a measure of weight adjusted for height, the BMI (Quetelet index), calculated as weight $(\mathrm{kg}) /$ height $(\mathrm{m})^{2}$. BMI is closely correlated with more sophisticated measures of obesity and, as such, is a useful screening tool (Després et al. 2001). It has been widely used in population studies and predicts the future development of diabetes (Chan et al. 1994; Lamon-Fava et al. 1996; Pyorala et al. 2000; von Eckardstein et al. 2000; Hu et al. 2001; Law \& Wald, 2002). The definitions of overweight and obesity have varied in different studies. The WHO definition of overweight is BMI $\geq 25 \mathrm{~kg} / \mathrm{m}^{2}$ and of obesity is BMI $\geq 30 \mathrm{~kg} / \mathrm{m}^{2}$ (World Health Organization, 1997). There is a progressive risk of obesity-related disease with increasing BMI within the normal range, above 20-22 $\mathrm{kg} / \mathrm{m}^{2}$ (World Health Organization, 2002). A limitation of $\mathrm{BMI}$ is that it is a composite of lean body mass and fat mass and does not take into account fat distribution. Women have a higher proportion of fat than men at each level of BMI. Individuals of South Asian descent have a higher proportion of body fat than those of European descent. In North Indian men a BMI of $21.4 \mathrm{~kg} / \mathrm{m}^{2}$ was associated with a mean percentage of body fat of $21.3 \%$ whereas in a European population an equivalent percentage body fat was associated with a mean BMI of $25 \cdot 2 \mathrm{~kg} / \mathrm{m}^{2}$ (Dudeja et al. 2001). Based on the results of this study it was suggested that a BMI $>22.5 \mathrm{~kg} / \mathrm{m}^{2}$ should be used to define overweight in South Asian men and BMI > $19 \mathrm{~kg} / \mathrm{m}^{2}$ to define overweight in South Asian women (Dudeja et al. 2001). Across other Asian populations, definitions for obesity have ranged from $\mathrm{BMI}>25 \mathrm{~kg} / \mathrm{m}^{2}$ to $\mathrm{BMI}>27 \cdot 5$ $\mathrm{kg} / \mathrm{m}^{2}$ (Deurenberg et al. 2002). In contrast, although there are considerable differences in body composition between individuals of Afro-Caribbean and European origin there is close correlation between BMI and total fat percentage. Therefore it is reasonable to use the same BMI indices of overweight and obesity in these populations (Gallagher et al. 1996; Fernandez et al. 2003) with the caveat that BMI is not a good measure of obesity in the elderly (Deurenberg et al. 1989; Rimm et al. 1995; Elia, 2001).

There are survival advantages for women to be able to store excess energy for future pregnancy; in particular 'pear-shaped' women with lower-body gynoid fat, rather than central android fat, may have no associated metabolic abnormalities (Brochu et al. 2001). Women with lowerbody obesity have more favourable fat metabolism with an increased suppression of upper-body-fat lipolysis, compared with those with more abdominal and upper-body fat (Martin \& Jensen, 1991). Waist circumference is particularly important in identifying a subgroup of the population having central android obesity, despite a BMI in the normal range (Han et al. 1995). Waist circumference is the best surrogate for visceral fat as measured by magnetic resonance imaging or computerised tomography scanning (Rankinen et al. 1999; Després et al. 2001) and identifies individuals with other features of the metabolic syndrome (von Eckardstein et al. 2000). Waist circumference measurement has been suggested as an alternative screening method to BMI to identify obese individuals (Lean et al. 1995; Janssen et al. 2002). Based on data from the MONICA study, a large epidemiological study of cardiovascular risk in multiple populations, height, BMI, age and population explained about $80 \%$ of the variance in waist circumference with BMI being the predominant determinant (Molarius et al. 1999). However, height, BMI, age group and population accounted only for $49 \%$ (men) and $30 \%$ (women) of the variation in WHR (Molarius et al. 1999). WHR in men largely reflects increasing waist circumference (Rankinen et al. 1999), and may be less useful than waist circumference alone in predicting the subsequent development of diabetes (Chan et al. 1994). WHR may be more useful in women in whom there is greater variety in the pattern of stored fat. Several factors are involved in determining whether women have predominantly lowerbody fat in a typical gynoid distribution, or whether they have an android or male pattern of central fat distribution. 
These factors include inherited tendencies and time of weight gain, with weight gained after the menopause also being important (Toth et al. 2000).

\section{Relevance of visceral adiposity: insulin resistance, metabolic syndrome, type 2 diabetes mellitus and coronary heart disease}

The increasing prevalence of obesity worldwide is having an important impact on the development of type 2 diabetes and CHD and it is therefore important to understand the factors contributing to body composition and the lean body mass:fat mass ratio. Both type 2 diabetes and IHD share risk factors in common, suggesting that these conditions share a common aetiology. Resistance to the biological actions of insulin or insulin resistance and the accompanying features of the metabolic syndrome are central to this shared aetiology.

Features of the metabolic syndrome could account for much of the increased risk of type 2 diabetes and CHD that occurs with obesity, although importantly the impact of these features of the metabolic syndrome differs between ethnic groups (for a review, see Anand et al. 2003). Interestingly, in African-Americans the prevalence of type 2 diabetes is increasing more rapidly than in Europeans; some of this increase may be attributable to the increased prevalence of obesity. In NHANES II conducted from 1976 to 1980 the prevalence of diabetes was $9.9 \%$ in AfricanAmericans compared with $6 \%$ in white Americans (Anand et al. 2003). Although differences in black and white cardiovascular mortality may in part be attributable to more prevalent hypertension and poverty, the increase in type 2 diabetes is also probably an important contributing factor. Although South Asians have an increased prevalence of and mortality from CHD than among European populations, individuals do not have increased traditional cardiovascular risk factors such as smoking, hypertension or increased LDL-cholesterol (Anand et al. 2003). In this ethnic group glucose intolerance, abdominal obesity and the metabolic syndrome features appear to be the dominant factors associated with the development of CHD. The cluster of features of the metabolic syndrome is also associated with decreased fibrinolysis, increased C-reactive protein, increased cytokines such as IL-6 and IL-1 $\beta$, and enhanced thrombogenesis, supporting the notion that there is evidence of disturbances of coagulation, fibrinolysis and vascular inflammation; all of these factors are particularly prevalent in South Asians. The explanation for these findings is uncertain but the features described earlier (p. 154) are strongly associated with the presence of visceral adiposity and insulin resistance in this ethnic group.

Therefore the programming of obesity in each ethnic group may differentially influence features of the metabolic syndrome, CHD and/or type 2 diabetes within individual populations. Consequently it is important to understand all of the factors contributing to the development of fat mass within population subgroups.

\section{Programming of the metabolic syndrome}

During early development the individual may respond to one or more insults by responding in a manner that, although immediately beneficial, has longer-term adverse consequences. Thus early adaptive changes may initially confer a benefit but if 'programmed' may confer a longerterm disadvantage. For example, a reduced birth weight may be a favourable response to an adverse intra-uterine environment but it is now well established that low birth weight is associated with the development of type 2 diabetes and CVD in adulthood.

Within the last decade Hales, Barker and colleagues have undertaken follow-up studies to determine whether lower birth weight as a marker of altered early development was related to the occurrence of the metabolic syndrome, impaired glucose tolerance (IGT) and type 2 diabetes (Hales et al. 1991; Hales \& Barker, 1992). To discover whether reduced fetal and infant growth is associated with type 2 diabetes and IGT in adult life, these investigators followed up men born during 1920-30 whose birth weights and weights at 1 year were known in Hertfordshire, England ( $n$ 468). This group of men, born in east Hertfordshire and still living there, had measurements taken of a range of biochemical parameters including fasting plasma glucose, insulin, pro-insulin, and 32-33 split proinsulin concentrations and plasma glucose and insulin concentrations 30 and 120 min after a 75 g glucose challenge. Of these men, ninety-three men had IGT or undiagnosed diabetes. These men also had had a lower mean birth weight and a lower weight at 1 year. The proportion of men with IGT fell progressively from $26 \%(6 / 23)$ among those who had weighed $8 \cdot 16 \mathrm{~kg}(18 \mathrm{lb})$ or less at 1 year to $13 \%$ $(3 / 24)$ among those who had weighed $12.25 \mathrm{~kg}(27 \mathrm{lb})$ or more. Corresponding values for diabetes were $17 \%(4 / 23)$ and nil (0/24). Plasma glucose concentrations at 30 and 120 min fell with increasing birth weight and weight at 1 year. Interestingly these trends were significant and independent of current body mass (Hales et al. 1991). The second study included 266 men and women born in Preston, UK, between 1935 and 1943 whose size at birth had been measured in detail (Hales \& Barker, 1992). The prevalence of the metabolic syndrome fell progressively in both men and women, from those who had the lowest to those who had the highest birth weight. Of 64-year-old men whose birth weight was $2.95 \mathrm{~kg}(6.5 \mathrm{lb})$ or less, $22 \%$ had the metabolic syndrome. Their risk of developing the metabolic syndrome was more than ten times greater than that of men whose birth weight was more than $4.31 \mathrm{~kg}(9 \cdot 5 \mathrm{lb})$. Importantly, the association between the metabolic syndrome and low birth weight was independent of the duration of gestation and of possible confounding variables including cigarette smoking, alcohol consumption and social class currently or at birth. Interestingly, in addition to low birth weight, subjects with the metabolic syndrome had smaller head circumference and lower ponderal index at birth, and lower weight and below-average dental eruption at 1 year of age compared with subjects who did not have the metabolic syndrome. The findings from these two studies suggested that the metabolic syndrome and type 2 diabetes in adulthood was associated with a generalised alteration in early development. Other investigators have more recently also described the association between low birth weight and increased rates of type 2 diabetes in later life in other populations (Lithell et al. 1996; Rich-Edwards et al. 1999; 
Forsen et al. 2000), providing further support for the original findings.

The available data also suggest that low birth weight is more closely associated with truncal fat deposition. Given the association between truncal fat and insulin resistance, an association between truncal fat and low birth weight may have important implications for the development of type 2 diabetes and CHD. In support of this statement, a group of 564 young adult Mexican-American and nonHispanic white men and women participants of the San Antonio Heart Study were studied. Subjects were divided into tertiles of birth weight and metabolic, anthropometric, haemodynamic, and demographic characteristics were compared across these tertile categories (Valdez et al. 1994). Birth weight was studied as a predictor of the clustering of diseases associated with the metabolic syndrome. Normotensive, non-diabetic individuals whose birth weight was in the lowest tertile had significantly higher levels of fasting serum insulin and more truncal fat deposition than individuals whose birth weight was in the highest tertile, independently of sex, ethnicity, and current socio-economic status. Thus, these data suggest that an altered early development predisposes to visceral fat accumulation and insulin resistance in these ethnic groups.

\section{Altered early development and rapid postnatal growth}

In attempting to explain the relationship between insulin resistance, IGT, type 2 diabetes and low birth weight, it is important to study the relationships between the accumulation of body fat in childhood and adult development of this phenotype occurring later in life. Low birth weight combined with rapid postnatal growth during infancy appears to be linked to an increased risk of obesity and its sequelae in later life. Rapid postnatal growth appears to be independent of birth weight and the timing of the adiposity rebound during mid-childhood is also an important predictor of later obesity. The timing, magnitude, and duration of adolescent growth and maturation are linked to critical changes in body composition, including the normal acquisition of body fat as shown in a study in Finland. A sample of 8760 men and women who were born at Helsinki University Central Hospital during 1934 and 1944, who attended child welfare clinics in the city of Helsinki, and who were still resident in Finland in 1971 were studied. On average, each individual had eighteen measurements of height and weight between birth and 12 years of age. The investigators identified a total of 290 individuals who had developed type 2 diabetes in adult life from the initial cohort of 10519 individuals who had birth and child welfare records. The cumulative incidence of type 2 diabetes decreased progressively from $8.6 \%$ in individuals whose adiposity rebound occurred before the age of 5 years to $1.8 \%$ in those in whom it occurred after 7 years $(P<0 \cdot 001)$. Early adiposity rebound was preceded by low weight gain between birth and 1 year $(P<0 \cdot 001)$. Thus, insulin resistance and type 2 diabetes share common associations with retarded fetal growth and accelerated growth during childhood. However, the authors concluded that insulin resistance and type 2 diabetes are dissimilar in that insulin resistance was associated with thinness in childhood and low maternal BMI, whilst type 2 diabetes was associated with high BMI in childhood and high maternal BMI. An explanation for this unusual finding is not forthcoming and further studies are required to confirm or refute the apparently different associations for insulin resistance and type 2 diabetes. Although the Finnish register did not distinguish between patients with type 1 and type 2 diabetes, these investigators had previously compared the national medication database with the national hospital discharge register and had shown that about $90 \%$ of those diagnosed after the age of 40 years and receiving medication had type 2 diabetes (Eriksson et al. 2002). To follow and predict adiposity rebound during childhood, individual adiposity curves assessed by the BMI were drawn for 151 children from the age of 1 month to 16 years of age in another study (Rolland-Cachera et al. 1984). These data show that adiposity increases during the first year of life and then thereafter decreases in childhood. A renewed rise (the adiposity rebound) occurs at about 6 years of age. This study also showed a relationship between the age at adiposity rebound and final adiposity. An early rebound (before $5 \cdot 5$ years of age) was followed by a significantly higher degree of adiposity than a later rebound (after 7 years of age). This phenomenon was observed whatever the subject's adiposity at 1 year of age. Thus, given the importance of the finding by Erikkson et al. (2002), an early adiposity rebound in childhood may contribute to adult adiposity, the metabolic syndrome and type 2 diabetes.

\section{Programming of fat mass}

The relationship between maternal nutrition and offspring adipocyte abnormalities has been studied over the last few decades and much of the original work has been undertaken in rats (Jones \& Friedman, 1982; Enns et al. 1983; Jones et al. 1984, 1986; Jones \& Dayries, 1990). Results from these authors show that when pregnant rats are underfed during gestation, offspring develop increased adipose tissue, although it should be noted that often differences in various parameters such as fat-cell size, fat-pad weight and carcass lipid content were noted between male and female offspring. However it is probable that the development of obesity and increased fat mass is not solely dependent on adipocyte proliferation and function. In considering the development of obesity and its relationship to features of the metabolic syndrome in man, it is particularly important and relevant to consider the two other major organs in the body that are specifically dependent upon the actions of insulin, namely the liver and skeletal muscle. Whole-body insulin resistance develops as a consequence of resistance to the biological actions of insulin in the liver, skeletal muscle and adipose tissue. Given the heterogeneity of the metabolic syndrome phenotype in adults, it is probable that different degrees of insulin resistance occurring in the liver, skeletal muscle and adipose tissues may affect the development of obesity. Moreover, insulin resistance in these tissues and other features of the metabolic syndrome will contribute to an increased risk of atherosclerotic vascular disease later in life. In a cohort of 4630 men who were born in Helsinki during 1934-44, 357 boys who in later life were either admitted to hospital with CHD or who had died 
from CHD were identified (Barker, 2002). Growth parameters were assessed in this cohort and growth was compared in individuals who had suffered CHD compared with controls. The results of this comparison were expressed as standard deviations or $Z$ scores. The $Z$ score for the cohort is set at zero, and a boy maintaining a steady position as large or small, in relation to other boys, would follow a horizontal path on the graph (Fig. 2). Interestingly, boys who later developed CHD were small at birth, remained small in infancy, but had accelerated gain in weight and BMI thereafter. By contrast, their heights remained below average, which is consistent with the known association between $\mathrm{CHD}$ and short adult stature. Findings in girls were similar, but among those who later developed CHD, accelerated weight gain began at about the age of 4 years. Thus, these data suggest that the timing of the 'adiposity rebound' is crucial and an earlier 'adiposity rebound' with increased weight gain, relative to height gain, predisposes to future CHD. These data suggest that an individual with an early adiposity rebound would be predisposed to a more 'rounded' adult shape, perhaps with central obesity and features of the metabolic syndrome.

Given that the timing of the 'adiposity rebound' is important in predisposing individuals to future obesity, it is important to consider whether maternal factors influence this development in the offspring. Specifically, does maternal energy deprivation during gestation influence body composition in the developing offspring? Data from the Dutch Famine Birth Cohort Study attempt to address this question. Records were examined for 734 women receiving at least 1 month of prenatal care and delivering live-born singleton females at the University of Amsterdam Teaching Hospital between August 1944 and April 1946 (Stein et al. 1995). This period preceded, encompassed, and followed the Hunger Winter, a severe famine. After adjusting for covariates, the authors found a threshold effect, with weight loss or low to moderate $(\leq 0.5 \mathrm{~kg} /$ week) weight gain being strongly associated with offspring birth weight, length, and ponderal index, and with trimester of famine exposure. Thus, these data suggest that the relationship between

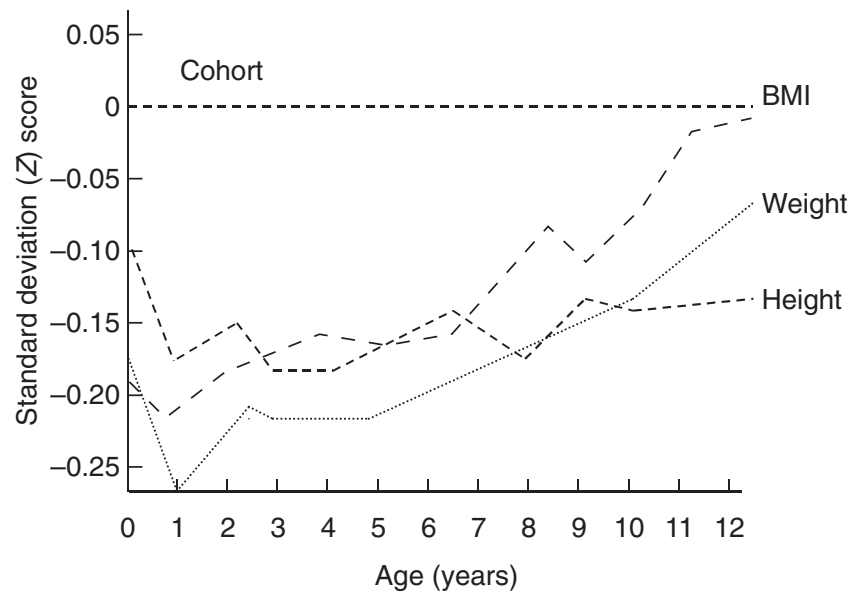

Fig. 2. Growth of 357 boys who later developed $C H D$ in a cohort of

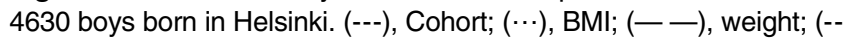
-), height. (Reproduced with permission from Trends in Endocrinology and Metabolism; Barker, 2002.) maternal nutrition and offspring body composition is complex. Acute maternal nutritional deprivation may only affect fetal growth below a threshold level of maternal energy intake and this effect seems not to be affected by the mother's own birth weight (Lumey \& Stein, 1997).

\section{Programming of obesity in different ethnic groups}

Given that it is now well established that South Asians are at increased risk of developing type 2 diabetes and CHD compared with Europeans, it is important to consider whether South Asians develop a greater fat mass relative to lean body mass during early development. Evidence of this phenomenon might suggest that the influence of early development on fat accumulation and distribution is relevant to the pathogenesis of type 2 diabetes and CHD. Interesting data from Pune in India suggest that early fat deposition is greater in South Asian offspring. Yajnik et al. (2002) showed that small Indian newborn babies preserve subcutaneous fat (measured as skinfold thickness) compared with white European babies. Subscapular adiposity was better preserved than the triceps adipose tissue. These data suggest a tendency in Indian babies to truncal fat deposition during intra-uterine development. Leptin levels, a marker of total body fat content, were similar in Indian and European babies. By contrast, Indian babies were small in abdominal circumference (suggesting smaller viscera) and small in mid-upper-arm circumference (suggesting smaller skeletal muscle mass). These findings suggest that Indian babies develop increased visceral adipose tissue and a reduced muscle mass compared with European offspring. Development of a reduced muscle mass may have little consequence in the presence of limited adult energy intake and high levels of physical activity. However, persistence of this South Asian body habitus into childhood and early adulthood may have more sinister consequences for the risk of CHD and type 2 diabetes, particularly if individuals consume an energy-dense Western diet and are physically inactive.

Relationships between early development and adult obesity may differ between ethnic groups. Recent interesting data from 267 singleton births from four ladino Guatemalan villages show that the relationships between early growth and adult fatness are complex (Li et al. 2003). Although these authors showed that both prenatal and postnatal growth retardation in early childhood during the first 2 years of life were associated with shortness and less fat-free mass in adulthood when the subjects were between 21 and 27 years, the results did not show that retardation in length during early childhood increased fatness in later life. In contrast, the findings suggested that subjects, particularly women, who were growth retarded during early childhood were thinner as adults. Thus, more data from different ethnic groups are needed to elucidate the precise relationship between early development and future levels of adiposity and lean mass in adulthood.

\section{Programming of lean body mass}

In considering the programming of obesity it is important to consider the early developmental influences on lean body 
mass and particularly muscle mass, as skeletal muscle activity has a major impact on insulin sensitivity. Given that BMI is a poor proxy for body composition (as discussed earlier; p. 154), it is important to assess lean mass and fat mass as components of body weight. It is probable that the programming of lean body mass and specifically skeletal muscle mass has an important impact on the development of features of the metabolic syndrome in adulthood. To date, however, there is limited information available to address this issue. However Singhal et al. (2003) assessed body fat mass and fat-free mass by both skinfold-thickness measurement and bioelectrical impedance analysis in seventy-eight adolescents aged between 13 and 16 years who were part of a study that investigated the early origins of CVD. Body composition was also assessed by dual-energy X-ray absorptiometry in a separate group of younger children. These authors showed that an increase in birth weight of 1 SD was significantly associated with a $0 \cdot 9-1 \cdot 4 \mathrm{~kg}(2-3 \%)$ increase in fat-free mass in adolescents but not with an increase in fat mass. This association was independent of age, sex, height, pubertal stage, and socio-economic status. In the study of the younger group of children from one of the communities (Cambridge), similar findings were observed. These observations suggest, therefore, that poor fetal growth, as measured by low birth weight, is associated with a smaller proportion of lean mass later in life. Since skeletal muscle mass (and physical activity) regulates insulin sensitivity, this finding may influence the development of adult obesity.

\section{Programming of behaviour, physical activity and energy intake}

Behaviour, energy intake and physical inactivity all have an important impact on obesity. If these factors were programmable during early development, the prevalence of the metabolic syndrome, type 2 diabetes and CHD may be influenced in adulthood. If behaviour were programmed such that increased energy intake and decreased energy expenditure occurred, it would be reasonable to predict that obesity and features of the metabolic syndrome might occur. In an interesting experiment utilising maternal undernutrition throughout pregnancy, Vickers et al. (2003) investigated whether prenatal influences led to alterations in postnatal locomotor behaviour (Fig. 3), independent of postnatal nutrition. Virgin Wistar rats were time-mated and randomly assigned to receive food either ad libitum (ad libitum group) or at $30 \%$ of ad libitum intake (undernourished group). The offspring from undernourished mothers were significantly smaller at birth than control offspring. At weaning, offspring were assigned to one of two diets (control or hyperenergetic (30\% fat)). At the ages of 35, 145 and $420 \mathrm{~d}$, voluntary locomotor activity was assessed. At all ages studied, the offspring from undernourished mothers were significantly less active than offspring born of normal birth weight for all parameters measured, independent of postnatal nutrition. Interestingly, sedentary behaviour in the programmed offspring was exacerbated by postnatal hyperenergetic nutrition (Fig. 4). Importantly the authors showed that predispositions to obesity, altered eating behaviour, and sedentary activity were linked and occurred independently of postnatal hyperenergetic nutrition. Moreover the prenatal influence may be permanent, as the offspring of undernourished mothers were still significantly less active compared with normal offspring at an advanced adult age, even in the presence of a healthy diet throughout postnatal life. This finding may have particularly important ramifications. If confirmed, the concept of programmed behaviour predisposing to adult disease adds another tier of complexity in attempting to treat and manage adult disease. Clearly, additional studies are necessary in other animal models to confirm or refute this finding.

Rats exposed to a reduced energy intake during gestation and a high-fat diet after weaning also develop greater appetites (Vickers et al. 2000; Breier et al. 2001). In this study adult rats subjected to this exposure were shorter and fatter than appropriately nourished controls. Furthermore, the rats in the latter group had lower blood pressures, decreased fasting plasma insulin and lower leptin concen-
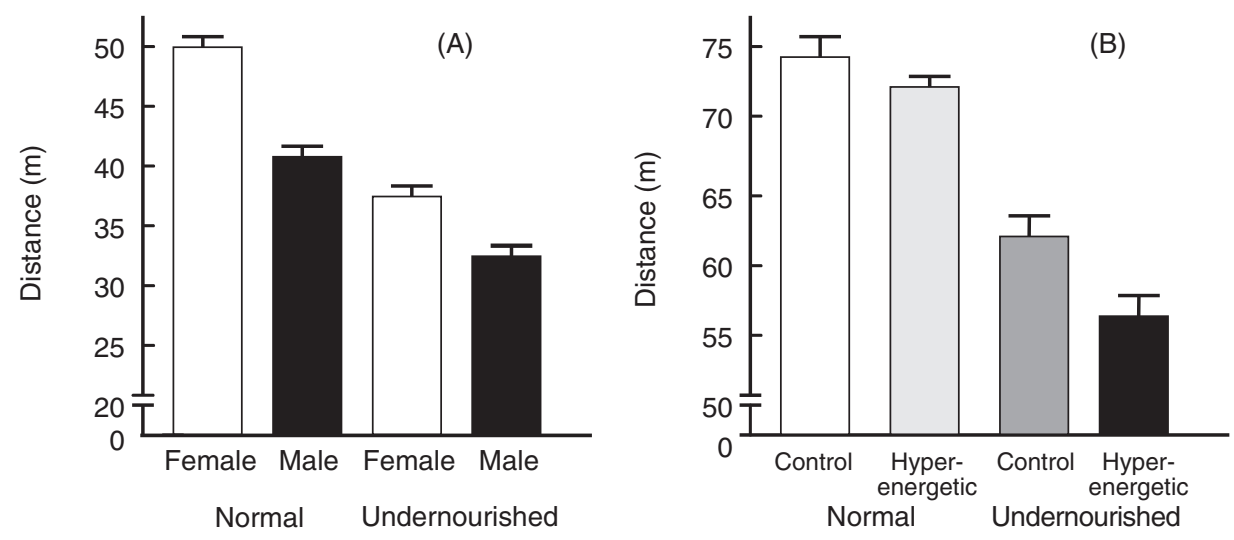

Fig. 3. Locomotor behaviour in Wistar rats as a consequence of a normal or adverse fetal environment ( $n$ 6-8 per group). (A) Locomotor activity at $35 \mathrm{~d}$ of age in males and females; $P<0.0001$ for effect of fetal programming and sex. (B) Locomotor activity at day 145 in females; $P<0.001$ for effect of fetal programming, $P<0.05$ for effect of hyperenergetic diet. Data were analysed by factorial ANOVA, and are shown as mean values, with their standard errors represented by vertical bars. (Reproduced with permission from American Journal of Physiology; Vickers et al. 2003.) 

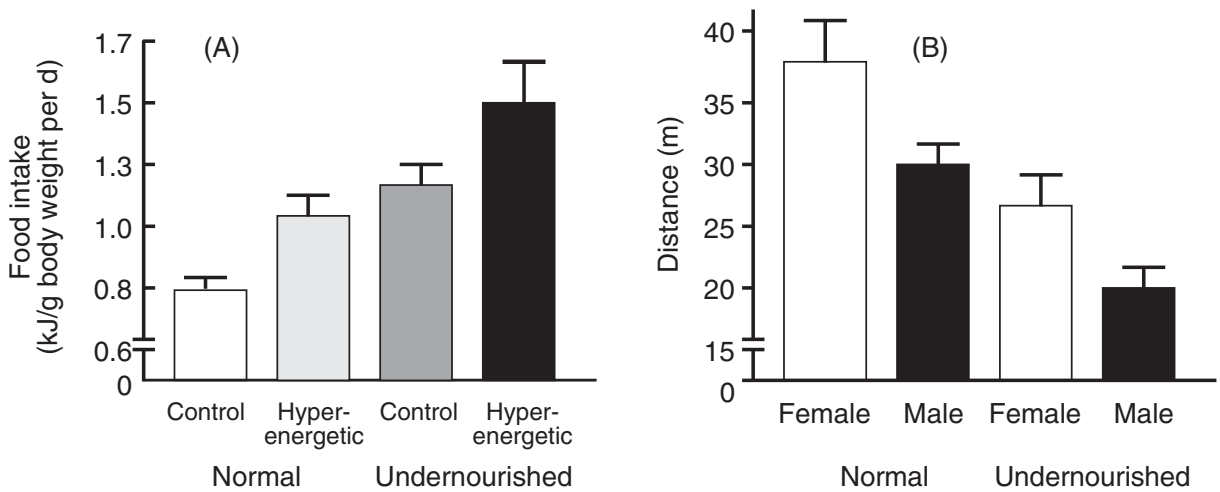

Fig. 4. Locomotor behaviour and food intake in Wistar rats as a consequence of a normal or adverse fetal environment ( $n 6-8$ per group). (A) Food intake (kJ/g body wt per d over a $5 \mathrm{~d}$ period) in females at day $145 ; P<0.005$ for effect of fetal programming, $P<0.05$ for postnatal hyperenergetic diet. (B) Locomotor activity at 14 months in males and females; $P<0.005$ for effect of fetal programming and sex. Data were analysed by factorial ANOVA, and are shown as mean values, with their standard errors represented by vertical bars. (Reproduced with permission from American Journal of Physiology, Vickers et al. 2003.)

trations. Thus, these data suggest that it is possible to programme appetite with important consequences for adult body composition.

Evidence is accumulating suggesting that a relationship between leptin and adipose content may be established in early life. Given that leptin is an important regulator of appetite, this relationship may have important implications for the development of adult obesity. A positive association has been described between the concentration of leptin in cord blood and adiposity at birth (Phillips et al. 1999). In a study of 502 men and women from the Hertfordshire cohort born in the 1920s and another study of 1462 women born between 1908 and 1930 (Lissner et al. 1999) the investigators have shown that, after adjustment for levels of current BMI, individuals who were small at birth had higher levels of leptin. Similar inverse relationships have also been described in pigs (Ekert et al. 2000); taken together these findings suggest leptin resistance in individuals with abnormal early development.

It also appears that infants with lower plasma leptin concentrations at birth and lower body weight tend to gain weight more rapidly in the first months of postnatal life (Ong et al. 1999), suggesting that it is the increased availability of nutrients postnatally that may be responsible for subsequent obesity. This may be an explanation for the findings of adult studies in the UK (Power \& Parsons, 2000) and Finland (Eriksson et al. 2001) showing that catch-up growth is associated with obesity. Whether the increased availability of nutrients programme leptin expression through the action of nutrient-sensitive hormones such as insulin or insulin-like growth factor-1 or whether these are direct effects on the adipocyte is presently uncertain.

Obesity and features of the metabolic syndrome may develop as a consequence of a programmed increase in appetite producing consequent weight gain, perhaps via a central effect in the hypothalamus. By reducing the litter size of rats to increase milk availability to the remaining pups, weight gain has been shown to occur rapidly in the remaining pups who become obese with features of the metabolic syndrome later in adult life (Plagemann et al.
1999). Interestingly these offspring had a marked increase in galanin-containing neurones in the arcuate nucleus of the hypothalamus, and galanin is a stimulator of food intake. Thus these data suggest that a factor or factors associated with increased food consumption, perhaps insulin or leptin or both, may modulate central appetite regulation producing adverse effects persisting into old age.

\section{Mechanisms underlying the programming of body composition}

The association between altered growth and CHD has led to the suggestion that the disease might originate from two phenomena associated with development; 'developmental, or phenotypic plasticity' and 'compensatory growth'. Phenotypic plasticity is the phenomenon whereby one genotype gives rise to a range of different physiological or morphological states in response to different environmental conditions during development (West-Eberhard, 1989, 1998). In considering the influence of genotype, Hattersley and Tooke have proposed that genetically determined insulin resistance results in impaired insulin-mediated growth in the fetus as well as insulin resistance in adult life. They have suggested that low birth weight, measures of insulin resistance in life, and ultimately glucose intolerance, diabetes, and hypertension could all be phenotypes of the same insulin-resistant genotype. In support of this proposal they suggest evidence to support the hypothesis. Insulin secreted by the fetal pancreas in response to maternal glucose concentrations is a key growth factor, and monogenic diseases that impair the sensing of glucose, reduce insulin secretion, or increase insulin resistance are associated with impaired fetal growth. For example, heterozygous mutations in the glucokinase gene associated with reduced insulin secretion, resulting from reduced glucose sensing by the pancreas, were linked to a $521 \mathrm{~g}$ decrease in birth weight in affected compared with unaffected siblings (Hattersley et al. 1998; Frayling \& Hattersley, 2001). These authors suggest that polygenic influences resulting in insulin resistance in the normal 
population are likely to result in lower birth weight. Moreover, they propose that abnormal vascular development during fetal life and early childhood, as a result of genetic insulin resistance, could also explain the increased risk of hypertension and vascular disease (Hattersley \& Tooke, 1999). Thus, these authors suggest that the link between early development, subsequent type 2 diabetes and vascular disease could be the result of interaction between both genetic and fetal environmental factors.

Gene-environment interactions are ubiquitous in development. Their existence is also demonstrated by the numerous experiments showing that minor alterations to the diets of pregnant animals, which may not even change their offspring's body size at birth, can produce lasting changes in their physiology and metabolism. These changes can include altered blood pressure, glucose and insulin metabolism and lipid metabolism (Kwong et al. 2000). Evidence of gene-nutrient interactions in the pathogenesis of altered body composition may be important in the aetiology of the metabolic syndrome. For example, differential activity of specific nuclear receptors may be involved in the pathogenesis of the programming of obesity. Nuclear receptors such as the peroxisomal proliferator-activated receptors (PPAR) utilise lipids, or their metabolites, as physiological ligand activators. After translocation to the cell nucleus these receptor-ligand complexes act to regulate gene transcription, particularly regulating genes involved in fat and glucose metabolism and also adipogenesis. Thus, variant activity of these receptor complexes would be key candidates responsible for influencing the programming of obesity and the metabolic syndrome. Interesting recent data are beginning to support this hypothesis. Eriksson et al. (2002) have shown an interaction between birth weight and a polymorphism of the gene encoding PPAR- $\gamma 2$ (PPARG2) in 476 elderly individuals in Helsinki. It has been suggested that the Pro12Ala polymorphism of the gene increases tissue sensitivity to insulin and thereby protects against type 2 diabetes. These authors showed that the Pro12Ala polymorphism only influenced fasting plasma insulin concentrations in men and women who had low birth weight. As expected, low birth weight was associated with increased plasma insulin concentrations as a marker of insulin resistance but was confined to individuals with the Pro12Pro polymorphism. The Pro12Ala polymorphism protected against this effect. Interestingly there was evidence of interaction between the effects of the gene polymorphism and birth weight $(P=0 \cdot 03$; Table 1$)$. Thus, these data provide interesting supporting evidence for interaction between a genotype that is known to be linked to altered function (PPAR- $\gamma 2$ Pro12Ala and insulin sensitivity) and early development (birth weight) that affects the adult phenotype (fasting insulin levels as a marker of insulin resistance).

Suboptimal nutrition in utero may also act directly to limit insulin secretion and consequently increase protein breakdown, potentially impairing fetal growth and development. Concentrations of insulin-like growth factor-1 may also be reduced, limiting intra-uterine muscle growth (Gluckman, 1997; Gluckman \& Harding, 1997). Therefore a pattern of growth may be established that would favour adipose formation, limited muscle mass accumulation and programming of the metabolic syndrome in adulthood.
Table 1. Mean fasting insulin concentration and homeostasis model assessment-insulin resistance index according to peroxisomal proliferator-activated receptor- $\gamma$ gene polymorphism and birth weight (reproduced with permission from Trends in Endocrinology and Metabolism; Barker, 2002)

\begin{tabular}{|c|c|c|c|c|}
\hline & \multicolumn{3}{|c|}{ Birth weight (g) } & \multirow[b]{3}{*}{$P^{*}$} \\
\hline & -3000 & -3500 & $>3500$ & \\
\hline & Mean $n$ & Mean $n$ & Mean $n$ & \\
\hline \multicolumn{5}{|l|}{ Fasting insulin (pmol/l) } \\
\hline $\begin{array}{l}\text { Pro12Pro } \\
\text { Pro12A1a/A1a12A1a } \\
P \dagger\end{array}$ & $\begin{array}{r}8456 \\
6037 \\
0.008\end{array}$ & $\begin{array}{cc}71 & 161 \\
60 & 67 \\
0.02\end{array}$ & $\begin{array}{c}65107 \\
6548 \\
0.99\end{array}$ & $\begin{array}{l}0.003 \\
0.31\end{array}$ \\
\hline
\end{tabular}

*Difference among birth-weight groups.

†Difference between the Pro12Pro and Pro12A1a/A1a12A1a genotypes.

Although increasing evidence supports the notion that adverse early development can have a marked and longlasting impact on an individual's later life, it has been proposed that modifying adult factors such as weight rather than influencing birth weight is the key to altering the adult phenotype (Huxley, 2002). In questioning the importance of early development to adult disease, it is stated that there is a lack of evidence for a 'dose-response' relationship between, for example, birth weight and hypertension (Zhao et al. 2002). It has been suggested that any association between birth weight and adult hypertension may be explained by confounding factors, influencing both low birth weight and the adult phenotype.

\section{Conclusion}

Increasing evidence is accumulating to support the concept of the programming of obesity. Factors contributing to the phenotype of obesity may also be altered during early development. These factors include genotype, behaviour, appetite, physical activity and body composition as discussed. Other factors not discussed in the present review include changes in hormonal axes (Byrne \& Phillips, 2000; Holt \& Byrne, 2002). For the future it will also be important to understand the regulatory mechanisms controlling each of these factors, and their interaction with offspring genotype. If we are to address the marked increase in prevalent worldwide obesity and type 2 diabetes, a better understanding of all factors regulating early growth and development, and all factors affecting adult body composition is crucial.

\section{References}

Anand SS Ounpuu S \& Yusuf S (2003) Ethnicity and cardiovascular disease. In Evidence-Based Cardiology, vol. II, 2nd ed., pp. 171-190 [S Yusuf, JA Cairns, AJ Camm, EL Fallen and BJ Gersh, editors]. London: BMJ Publishing Group.

Barker DJ (2002) Foetal programming of coronary heart disease. Trends in Endocrinology and Metabolism 13, 364-368.

Breier BH, Vickers MH, Ikenasio BA, Chan KY \& Wong WPS (2001) Foetal programming of appetite and obesity. Molecular and Cellular Endocrinology 185, 73-79.

Brochu M, Tchernof A, Dionne IJ, Sites CK, Eltabbakh GH, Sims EAH \& Poehlman ET (2001) What are the physical characteris- 
tics associated with a normal metabolic profile despite a high level of obesity in postmenopausal women? Journal of Clinical Endocrinology and Metabolism 86, 1020-1025.

Byrne CD \& Phillips DI (2000) Fetal origins of adult disease: epidemiology and mechanisms. Journal of Clinical Pathology 53, 822-828.

Chan JM, Rimm EB, Colditz GA, Stampfer MJ \& Willett WC (1994) Obesity, fat distribution, and weight gain as risk factors for clinical diabetes in men. Diabetes Care 17, 961-969.

Després JP, Lemieux I \& Prud'homme D (2001) Treatment of obesity: need to focus on high risk abdominally obese patients. British Medical Journal 322, 716-720.

Deurenberg P, Deurenberg-Yap M \& Guricci S (2002) Asians are different from Caucasians and from each other in their body mass index/body fat per cent relationship. Obesity Reviews 3, 141-146.

Deurenberg P, van der Kooy K, Hulshof T \& Evers P (1989) Body mass index as a measure of body fatness in the elderly. European Journal of Clinical Nutrition 43, 231-236.

Dudeja V, Misra A, Pandey RM, Devina G, Kumar G \& Vikram NK (2001) BMI does not accurately predict overweight in Asian Indians in northern India. British Journal of Nutrition 86, 105-112.

Ekert JE, Gatford KL, Luxford BG, Campbell RG \& Owens PC (2000) Leptin expression in offspring is programmed by nutrition in pregnancy. Journal of Endocrinology 165, R1-R6.

Elia M (2001) Obesity in the elderly. Obesity Research 9, Suppl. 4, 244S-248S.

Enns MP, Wilson MW, Grinker JA, Faust IM, Jones AP, Friedman MI (1983) Prenatal food restriction and subsequent weight gain in male rats. Science 219, 1093-1094.

Eriksson JG, Forsen T, Tuomilehto J, Jaddoe VW, Osmond C \& Barker DJ (2002) Effects of size at birth and childhood growth on the insulin resistance syndrome in elderly individuals. Diabetologia 45, 342-348.

Eriksson JG, Forsén T, Tuomilehto J, Osmond C \& Barker D (2001) Size at birth, childhood growth and obesity in later life. International Journal of Obesity and Related Metabolic Disorders 25, 735-740.

Fernandez JR, Heo M, Heymsfield SB, Pierson RN, Pi-Sunyer FX, Wang ZM, Wang J, Hayes M, Allison DB \& Gallagher D (2003) Is percentage body fat differentially related to body mass index in Hispanic Americans, African Americans, and European Americans? American Journal of Clinical Nutrition 77, 71-75.

Forsen T, Eriksson J, Tuomilehto J, Reunanen A, Osmond C \& Barker D (2000) The foetal and childhood growth of persons who develop type 2 diabetes. Annals of Internal Medicine 133, 176-182.

Frayling TM \& Hattersley AT (2001) The role of genetic susceptibility in the association of low birth weight with type 2 diabetes. British Medical Bulletin 60, 89-101.

Gallagher D, Visser M, Sepulveda D, Pierson RN, Harris T \& Heymsfield SB (1996) How useful is body mass index for comparison of body fatness across age, sex, and ethnic groups? American Journal of Epidemiology 143, 228-239.

Gluckman PD (1997) Endocrine and nutritional regulation of prenatal growth. Acta Paediatrica 423, Suppl., 153-157.

Gluckman PD \& Harding JE (1997) Foetal growth retardation: underlying endocrine mechanisms and postnatal consequences. Acta Paediatrica 422, Suppl., 69-72.

Hales CN \& Barker DJ (1992) Type 2 (non-insulin-dependent) diabetes mellitus: the thrifty phenotype hypothesis. Diabetologia 35, 595-601.

Hales CN, Barker DJ, Clark PM, Cox LJ, Fall C, Osmond C \& Winter PD (1991) Foetal and infant growth and impaired glucose tolerance at age 64. British Medical Journal 303, 1019-1022.
Han TS, van Leer EM, Seidell JC \& Lean MEJ (1995) Waist circumference action levels in the identification of cardiovascular risk factors: prevalence study in a random sample. British Medical Journal 311, 1401-1405.

Hattersley AT, Beards F, Ballantyne E, Appleton M, Harvey R \& Ellard S (1998) Mutations in the glucokinase gene of the fetus result in reduced birth weight. Nature Genetics 19, 268-270.

Hattersley AT \& Tooke JE (1999) The fetal insulin hypothesis: an alternative explanation of the association of low birthweight with diabetes and vascular disease. Lancet 353, 1789-1792.

Holt RIG \& Byrne CD (2002) Intrauterine growth, the vascular system and the metabolic syndrome. Seminars in Vascular Medicine 2, 33-44.

Hu FB, Manson JE, Stampfer MJ, Colditz G, Liu S, Solomon CG $\&$ Willett WC (2001) Diet, lifestyle, and the risk of type 2 diabetes mellitus in women. New England Journal of Medicine 345, 790-797.

Huxley R (2002) Commentary: modifying body weight not birthweight is the key to lowering blood pressure. International Journal of Epidemiology 31, 1051-1053.

Janssen I, Katzmarzyk PT \& Ross R (2002) Body mass index, waist circumference, and health risk: evidence in support of current national institutes of health guidelines. Archives of Internal Medicine 162, 2074-2079.

Jones AP, Assimon SA \& Friedman MI (1986) The effect of diet on food intake and adiposity in rats made obese by gestational undernutrition. Physiology and Behavior 37, 381-386.

Jones AP \& Dayries M (1990) Maternal hormone manipulations and the development of obesity in rats. Physiology and Behavior 47, 1107-1110.

Jones AP \& Friedman MI (1982) Obesity and adipocyte abnormalities in offspring of rats undernourished during pregnancy. Science 215, 1518-1519.

Jones AP, Simson EL \& Friedman MI (1984) Gestational undernutrition and the development of obesity in rats. Journal of Nutrition 114, 1484-1492.

Kwong WY, Wild AE, Roberts P, Willis AC \& Fleming TP (2000) Maternal undernutrition during the preimplantation period of rat development causes blastocyst abnormalities and programming of postnatal hypertension. Development 127, 4195-4202.

Lamon-Fava S, Wilson PW \& Schaefer EJ (1996) Impact of body mass index on coronary heart disease risk factors in men and women. The Framingham Offspring Study. Arteriosclerosis, Thrombosis, and Vascular Biology 16, 1509-1515.

Law MR \& Wald NJ (2002) Risk factor thresholds: their existence under scrutiny. British Medical Journal 324, 1570-1576.

Lean MEJ, Han TS \& Morrison CE (1995) Waist circumference as a measure for indicating need for weight management. British Medical Journal 311, 158-161.

Li H, Stein AD, Barnhart HX, Ramakrishnan U \& Martorell R (2003) Associations between prenatal and postnatal growth and adult body size and composition. American Journal of Clinical Nutrition 77, 1498-1505.

Lissner L, Karlsson C, Lindroos AK, Carlsson B, Carlsson L \& Bengtsson C (1999) Birth weight, adulthood BMI, and subsequent weight gain in relation to leptin levels in Swedish women. Obesity Research 7, 150-154.

Lithell HO, McKeigue PM, Berglund L, Mohsen R, Lithell UB \& Leon DA (1996) Relation of size at birth to non-insulin dependent diabetes and insulin concentrations in men aged 50-60 years. British Medical Journal 312, 406-410.

Lumey LH \& Stein AD (1997) Offspring birth weights after maternal intrauterine undernutrition: a comparison within sibships. American Journal of Epidemiology 146, 810-819.

Martin ML \& Jensen MD (1991) Effects of body fat distribution on regional lipolysis in obesity. Journal of Clinical Investigation 88, 609-613. 
Molarius A, Seidell JC, Sans S, Tuomilehto J \& Kuulasmaa K (1999) Waist and hip circumferences, and waist-hip ratio in 19 populations of the WHO MONICA Project. International Journal of Obesity and Related Metabolic Disorders 23, 116-125.

Ong KKL, Ahmed ML, Sherriff A, Woods KA, Watts A, Golding J \& Dunger DB (1999) Cord blood leptin is associated with size at birth and predicts infancy weight gain in humans. Journal of Clinical Endocrinology and Metabolism 84, 1145-1148.

Ozanne SE, Lewis R, Jennings BJ \& Hales CN (2003) Early programming of weight gain in mice prevents the induction of obesity by a highly palatable diet. Clinical Science (London) 106, 141-145.

Peeters A, Barendregt JJ, Willekens F, Mackenbach JP, Al Mamun A \& Bonneux L (2003) Obesity in adulthood and its consequences for life expectancy: a life-table analysis. Annals of Internal Medicine 7, 24-32.

Phillips DIW, Fall CHD, Cooper C, Norman RJ, Robinson JS \& Owens PC (1999) Size at birth and plasma leptin concentrations in adult life. International Journal of Obesity 23, 1025-1029.

Plagemann A, Harder T, Rake A, Voits M, Fink H, Rohde W \& Dorner G (1999) Perinatal elevation of hypothalamic insulin, acquired malformation of hypothalamic galaninergic neurons, and syndrome X-like alterations in adulthood of neonatally overfed rats. Brain Research 836, 146-155.

Power C \& Parsons T (2000) Nutritional and other influences in childhood as predictors of adult obesity. Proceedings of the Nutrition Society 59, 267-272.

Pyorala M, Miettinen H, Halonen P, Laakso M \& Pyorala K (2000) Insulin resistance syndrome predicts the risk of coronary heart disease and stroke in healthy middle-aged men: the 22year follow-up results of the Helsinki Policemen Study. Arteriosclerosis, Thrombosis, and Vascular Biology 20, 538-544.

Rankinen T, Kim SY, Perusse L, Despres JP \& Bouchard C (1999) The prediction of abdominal visceral fat level from body composition and anthropometry: ROC analysis. International Journal of Obesity and Related Metabolic Disorders 23, 801-809.

Ravussin E \& Bogardus C (2000) Energy balance and weight regulation. British Journal of Nutrition 83, Suppl. 1, S17-S20.

Rich-Edwards JW, Colditz GA, Stampfer MJ, Willett WC, Gillman MW, Hennekens CH, Speizer FE \& Manson JE (1999) Birthweight and the risk for type 2 diabetes mellitus in adult women. Annals of Internal Medicine 130, 278284.

Rimm EB, Stampfer MJ, Giovannucci E, Ascherio A, Spiegelman D, Colditz GA \& Willett WC (1995) Body size and fat distribution as predictors of coronary heart disease among middle-aged and older US men. American Journal of Epidemiology 141, $1117-1127$

Rogers I (2003) The influence of birthweight and intrauterine environment on adiposity and fat distribution in later life. International Journal of Obesity and Related Metabolic Disorders 27, 755-777.
Rolland-Cachera M-F, Deheeger M, Bellisle F, Sempe M, Guilloud-Bataille M \& Patois E (1984) Adiposity rebound in children: a simple indicator for predicting obesity. American Journal of Clinical Nutrition 39, 129-135.

Singhal A, Wells J, Cole TJ, Fewtrell M \& Lucas A (2003) Programming of lean body mass: a link between birth weight, obesity, and cardiovascular disease? American Journal of Clinical Nutrition 77, 726-730.

Stein AD, Ravelli AC \& Lumey LH (1995) Famine, thirdtrimester pregnancy weight gain, and intrauterine growth: the Dutch Famine Birth Cohort Study. Human Biology 67, $135-150$

Toth MJ, Sites CK, Eltabbakh GH \& Poehlman ET (2000) Effect of menopausal status on insulin-stimulated glucose disposal: comparison of middle-aged premenopausal and early postmenopausal women. Diabetes Care 23, 801-806.

Valdez R, Athens MA, Thompson GH, Bradshaw BS \& Stern MP (1994) Birthweight and adult health outcomes in a biethnic population in the USA. Diabetologia 37, 624-631.

Vickers MH, Breier BH, Cutfield WS, Hofman PL \& Gluckman PD (2000) Foetal origins of hyperphagia, obesity, and hypertension and postnatal amplification by hypercaloric nutrition. American Journal of Physiology 279, E83-E87.

Vickers MH, Breier BH, McCarthy D \& Gluckman PD (2003) Sedentary behavior during postnatal life is determined by the prenatal environment and exacerbated by postnatal hypercaloric nutrition. American Journal of Physiology 285, R271-R273.

von Eckardstein A, Schulte H \& Assmann G (2000) Risk for diabetes mellitus in middle-aged Caucasian male participants of the PROCAM Study: implications for the definition of impaired fasting glucose by the American Diabetes Association. Journal of Clinical Endocrinology and Metabolism 85, 3101-3108.

West-Eberhard MJ (1989) Phenotypic plasticity and the origins of diversity. Annual Review of Ecology and Systematics 20, 249-278.

West-Eberhard MJ (1998) Evolution in the light of developmental and cell biology, and vice versa. Proceedings of the National Academy of Science USA 95, 8417-8419.

World Health Organization (1997) Obesity: Preventing and Managing the Global Epidemic - Report of a WHO Consultation on Obesity. Geneva: WHO.

World Health Organization (2002) Quantifying selected major risks to health. In World Health Report: Reducing Risks, Promoting Healthy Life, chapter 4. Geneva: WHO.

Yajnik CS, Lubree HG, Rege SS, Naik SS, Deshpande JA, Deshpande JA, Joglekar CV \& Yudkin JS (2002) Adiposity and hyperinsulinemia in Indians are present at birth. Journal of Clinical Endocrinology and Metabolism 87, 5575-5580.

Zhao M, Shu XO, Jin F, Yang G, Li H, Liu D, Wen W, Gao Y \& Zheng W (2002) Birthweight, childhood growth and hypertension in adulthood. International Journal of Epidemiology 31, 1043-1051. 